\title{
Qualidade da água do Rio Cuiabá para irrigação, na região metropolitana da capital Mato-Grossense
}

A agricultura irrigada promove o aumento de produtividade nos sistemas agrícolas, no entanto, há necessidade de se observar tanto a quantidade, quanto a qualidade da água disponível a fim de se viabilizar a produção e a segurança dos alimentos e da água a ser utilizada. Portanto, este trabalho teve como objetivo avaliar os riscos de salinidade, sodicidade, infiltração e toxicidade, com intuito de diagnosticar e monitorar a qualidade da água do Rio Cuiabá, na região metropolitana de Cuiabá. Foram analisadas as principais variáveis físicas, químicas e microbiológicas que definem a qualidade da água para irrigação: Temperatura, $\mathrm{pH}$, condutividade elétrica, razão de adsorção de sódio, $\mathrm{Ca} 2+, \mathrm{Mg} 2+, \mathrm{Na}+, \mathrm{K}+, \mathrm{Cl}-$, SO4++, N-total, P-total, Sólidos Totais, Turbidez e Escherichia coli. Foram utilizados dados da SEMA referente a cinco pontos ao longo do percurso urbano do Rio Cuiabá nos períodos de janeiro de 2011 a novembro de 2017 , abrangendo tanto o período chuvoso, quanto o período de seca. Nos pontos observados não foram identificados restrições de uso da água na irrigação quanto às variáveis físicas e químicas. A maioria dos pontos possui restrições quanto ao aspecto microbiológico, demonstrando, portanto, necessidade de maiores investigações quanto ao uso e fontes contaminantes nestas águas.

Palavras-chave: Agricultura irrigada; Contaminação; Cinturão verde.

\section{Cuiabá River water quality for irrigation, in the metropolitan region of Mato Grosso capital}

\begin{abstract}
Irrigated agriculture promotes increased productivity in agricultural systems, however, there is a need to observe both the quantity and the quality of the water available in order to facilitate the food production and safety and water to be used. Therefore, this study aimed to evaluate the risk of salinity, sodicity, infiltration and toxicity, in order to diagnose and monitor the water quality of the Cuiabá River, in the metropolitan region of Cuiabá. It was analyzed the main physical chemical and microbiological variables that define the quality of irrigation water: temperature, $\mathrm{pH}$, electric conductivity, sodium adsorption ratio, $\mathrm{Ca2} 2, \mathrm{Mg} 2+$ $\mathrm{Na+}, \mathrm{K}+, \mathrm{Cl}-$, SO4++, N-, P-total, total solids, Turbidity and Escherichia coli. SEMA data were used for five points along the Cuiabá River urban route in January 2011 to November 2017, covering both the rainfall and drought seasons. In the observed points, there were not identified restrictions on water use in irrigation with regard to physical and chemical variables. Most of the points have restrictions on the microbiological aspect, demonstrating, therefore, the necessity of further investigations regarding the use and sources contaminants in these waters.
\end{abstract}

Keywords: Agriculture; Contamination; Green belt.

Topic: Engenharia Ambiental

Reviewed anonymously in the process of blind peer
Received: 02/10/2019

Approved: 26/11/2019
Carine Schmitt Gregolin Caloi (iD

Universidade do Estado de Mato Grosso, Brasil

http://lattes.cnpq.br/381295

http://orcid.org/0000-0002-0349-3977

carine.schmitt@gmail.com

\section{Margarida Marchetto (iD}

Universidade Federal de Mato Grosso, Brasil

http://lattes.cnpq.br/8661520853211077

http://orcid.org/0000-0002-8422-943X

marchetto.ro@gmail.com

Tadeu Miranda de Queiroz (iD)

Universidade do Estado de Mato Grosso, Brasil

http://lattes.cnpq.br/2582121765769124

http://orcid.org/0000-0002-1959-7658

tdmqueiroz@yahoo.com.br

\author{
Patrícia Alana dos Santos Campos \\ Universidade Federal de Mato Grosso, Brasi \\ http://lattes.cnpq.br/6955891599394563 \\ http://orcid.org/0000-0003-1023-8074 \\ patricialana.sc@gmail.com \\ Ana Julian de Almeida Amorim (iD \\ Universidade Federal de Mato Grosso, Brasil \\ http://lattes.cnpq.br/4256843553535583 \\ http://orcid.org/0000-0001-5691-9735 \\ anajulian.amorim@gmail.com
}

Referencing this:

CALOI, C. S. G.; MARCHETTO, M.; QUEIROZ, T. M.; CAMPOS, P. A. S.; AMORIM, A. J. A.. Qualidade da água do Rio Cuiabá para irrigação, na região metropolitana da capital Mato-Grossense. Revista Ibero Americana de Ciências Ambientais, v.10, n.6, p.241-250, 2019. DOI: http://doi.org/10.6008/CBPC2179-6858.2019.006.0021

DOI: 10.6008/CBPC2179-6858.2019.006.0021 


\section{INTRODUÇÃO}

A qualidade da água para uso na irrigação tomou relevância vista a necessidade da conservação dos recursos hídricos e da pressão que este vem tendo devido a sua utilização. A agricultura é a atividade que mais utiliza dos recursos hídricos, e terá, futuramente, que adequar-se ao uso de águas com qualidade inferior, gerando reflexos negativos na agricultura irrigada, limitando o desenvolvimento agrícola (ANA, 2017). Conforme Marchetto et al. (2018), o enquadramento ainda não foi implementado no estado de Mato Grosso, as águas recebem a classificação 2, baseadas na Resolução CONAMA 357/2005.

A agricultura irrigada necessita tanto de quantidade, quanto de qualidade da água utilizada, e a qualidade pode variar significativamente segundo o tipo e quantidade de sais dissolvidos, além de contemplar o conjunto de características físicas, químicas e biológicas que definem sua adequação ou não para uso (ALMEIDA, 2010; AYERS et al., 1991). A má qualidade da água utilizada na irrigação é normalmente identificada no entorno de áreas urbanizadas, que apesar de avanços no saneamento básico nos últimos anos, ainda há contaminação devido descargas irregulares de dejetos, nas quais as plantas possuem sensibilidade a diferentes contaminantes presentes e, de suas concentrações, gerando queda no rendimento ou inviabilização total ou parcial da atividade agrícola (ANA, 2017).

Neste contexto, encontra-se a Bacia do Rio Cuiabá, um dos principais contribuintes do Pantanal, localizada na região central da bacia do Alto Paraguai e, segundo Araújo et al. (2011) sofreu nas décadas de 70 e 80 crescimento intenso das atividades agrícolas e populacional, como de centros urbanos, gerando demanda diversificada no uso das águas do Rio Cuiabá e, em contrapartida, o aumento de cargas orgânicas, nutrientes e coliformes gerados pelos esgotos domésticos, como das fontes vinculadas às atividades agrícolas e criações de animais nas pequenas propriedades rurais em seu entorno.

Destarte, a avaliação da qualidade das águas do Rio Cuiabá para uso agrícola torna-se importante meio para efetivar a gestão dos recursos hídricos e reduzir os impactos à longo prazo sobre o Pantanal Matogrossense, além de voltar à atenção ao uso desta água por pequenas propriedades no entorno das áreas urbanas das cidades de Cuiabá e Várzea Grande.

Este estudo se justifica devido ao incremento da demanda dos diversos usos das águas, causado pela ocupação urbana, aumento das atividades agrícolas e criação de animais nas pequenas propriedades rurais ao entorno do Rio Cuiabá (LIMA, 2001, citado por OLIVEIRA et al., 2017), além da existência de horticultores nas áreas urbanas e periurbanas, cujos produtos são comercializados em feiras da capital Mato-grossense, que levantam preocupações quanto ao risco de uso de água contaminada, possibilitando novas situações de perigo à saúde pública (ALMEIDA et al., 2016), advindas de lançamento de efluentes tratados e clandestinos provenientes dos córregos urbanos que deságuam no rio Cuiabá (KREISCHER et al., 2012), sendo provável que a água contenha elevadas concentrações de bactérias termotolerantes, turbidez e sólidos totais, podendo contaminar os alimentos e causar danos aos equipamentos, conforme o método de irrigação empregado. $\mathrm{O}$ objetivo deste trabalho foi avaliar a qualidade da água para fins de irrigação em 05 pontos de monitoramento com estações Hidroweb no Rio Cuiabá, localizado em Cuiabá, capital do Mato Grosso, 
classificando-as de acordo com os limites estabelecidos pela literatura clássica específica e a legislação.

\section{MATERIAIS E MÉTODOS}

\section{Área de estudo}

De acordo com PCBAP (1997), a bacia hidrográfica do rio Cuiabá, situado no Estado de Mato Grosso, totaliza aproximadamente $29.000 \mathrm{~km}^{2}$ de área, com perímetro de $841 \mathrm{~km}$, abrangendo as cabeceiras dos rios Cuiabá da Larga e Cuiabá do Bonito, que são os principais formadores do rio Rio Cuiabá. À montante da área de estudo estão inseridos os municípios de: Rosário Oeste, Nobres, Jangada, Nova Brasilândia, Chapada dos Guimarães, Planalto da Serra, e, entre esses, Cuiabá e Várzea Grande, principais núcleos urbanos do estado, localizados no trecho avaliado. (AMORIM, 2013; MATO GROSSO, 1996) A bacia hidrográfica está localizada entre os paralelos $14^{\circ} 18^{\prime}$ e $17^{\circ} 00^{\prime}$ e entre os meridianos $54^{\circ} 40^{\prime}$ e $56^{\circ} 55^{\prime} \mathrm{W}$ (CAVINATTO, 1995; MARCHETTO et al., 2019) no estado de Mato Grosso. Na região do médio curso do Rio Cuiabá estão localizados os aglomerados urbanos de Cuiabá e Várzea Grande, que concentram expressiva população do estado (SEMA, 2018). Seus principais afluentes a montante da região metropolitana são os rios: Marzagão, Manso, Acorizal, Coxipó-Açú, Coxipó, pela margem esquerda e pela margem direita o Chiqueirão, Jangada, Espinheiro e Piraim (Mato Grosso, 2010).

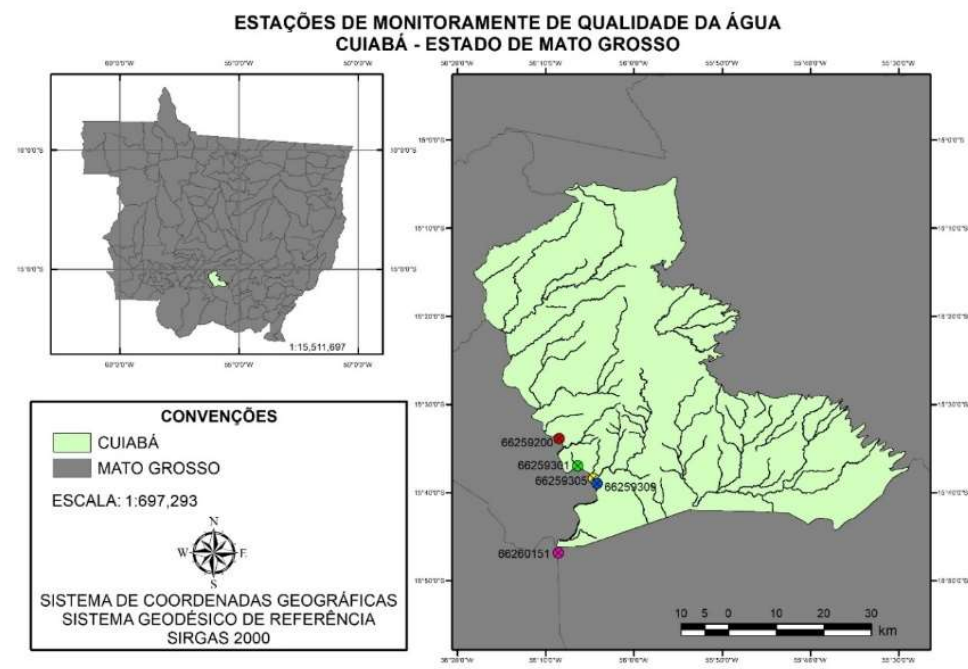

Figura 1: Delimitação dos pontos abordados na região metropolitana do rio Cuiabá. Fonte: Marchetto et al. (2019).

\section{Dados de qualidade da água}

O levantamento e a sistematização dos dados de análises físico-químicas e bacteriológica da água utilizados para este trabalho foram coletados, e são disponíveis ao público, no site da Secretaria de Estado de Meio Ambiente -SEMA (2018). Os dados utilizados são referentes aos meses de janeiro, maio e setembro do ano de 2011; fevereiro, julho e outubro de 2012; fevereiro, junho e outubro de 2013; fevereiro, maio e outubro de 2014; abril e setembro de 2015; fevereiro, junho, agosto e novembro de 2016; fevereiro, maio, agosto e novembro de 2017, totalizando 22 repetições, sendo 9 no período chuvoso (nov-abr) e 13 no período seco (mai-out). As variáveis de qualidade da água utilizadas neste estudo foram: Cálcio $\left(\mathrm{Ca}^{2+}\right)$, Magnésio $\left(\mathrm{Mg}^{2+}\right)$, Potássio $\left(\mathrm{K}^{+}\right)$, Sódio $\left(\mathrm{Na}^{+}\right)$, Cloreto $\left(\mathrm{Cl}^{-}\right)$, Escherichia Coli, Condutividade elétrica (CE), 
temperatura $\left({ }^{\circ} \mathrm{C}\right)$, sulfatos $\left(\mathrm{SO}_{4}{ }^{++}\right)$, nitrogênio total $(\mathrm{N}$-Total), fósforo total (P-Total), sólidos totais $(\mathrm{ST})$, turbidez e pH. Foram utilizados dados de cinco pontos de monitoramento no rio Cuiabá, disponíveis no Sistema de Informações Hidrológicas - HIDROWEB da Agência Nacional de Águas, conforme a Tabela 1.

Tabela 1: Informações das estações de monitoramento do Rio Cuiabá, na região metropolitana da capital de Mato Grosso.

\begin{tabular}{|c|c|c|c|c|}
\hline Nome & Código HIDROWEB & Código da Estação & Coordenadas UTM $(\mathrm{X} ; \mathrm{Y})$ & Altitude $(\mathrm{m})$ \\
\hline $\mathrm{EPC}^{\mathrm{a}}$ & 66259200 & CBA406 & $15^{\circ} 33^{\prime} 53.52^{\prime \prime} \mathrm{S} ; 56 \circ 8^{\prime} 29.83^{\prime \prime} \mathrm{W}$ & 156 \\
\hline EJCMPb & 66259301 & CBA408 & $15^{\circ} 36^{\prime} 58.1^{\prime \prime} \mathrm{S} ; 56^{\circ} 6^{\prime} 22.53^{\prime \prime} \mathrm{W}$ & 153 \\
\hline $\mathrm{EJCB}^{\mathrm{C}}$ & 66259305 & CBA415 & $15^{\circ} 38^{\prime} 25.66^{\prime \prime} \mathrm{S} ; 56^{\circ} 4^{\prime} 35.18^{\prime \prime} \mathrm{W}$ & 147 \\
\hline EJCSG $^{d}$ & 66259309 & CBA417 & $15^{\circ} 39^{\prime} 0.21^{\prime \prime} \mathrm{S} ; 56^{\circ} 04^{\prime} 11.61^{\prime \prime} \mathrm{W}$ & 147 \\
\hline ERCe & 66260151 & CBA437 & $15^{\circ} 46^{\prime} 51.03^{\prime \prime} \mathrm{S} ; 56008^{\prime} 34.59^{\prime \prime} \mathrm{W}$ & 146 \\
\hline
\end{tabular}

${ }^{a}$ Estação Passagem da Conceição; ${ }^{b}$ Estação Jusante Córrego Mané Pinto; ${ }^{C}$ Estação Jusante Córrego Barbado; ${ }^{d}$ Estação

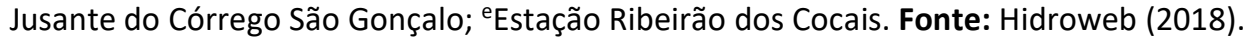

A qualidade da água para irrigação foi definida em função dos critérios de salinidade, sodicidade, toxicidade e risco de infiltração (ALMEIDA, 2010; AYERS et al., 1991). A Razão de Adsorção de Sódio (RAS) foi calculada com os dados de $\mathrm{Ca}^{+2}, \mathrm{Mg}^{+2}$ e $\mathrm{Na}^{+}$transformados de $\mathrm{mg} \mathrm{L}^{-1}$ para meq $\mathrm{L}^{-1}$ que é numericamente igual a mmol $\mathrm{L}^{-1}$, e usado o software livre Qualigraf 1.1 para avaliação e elaboração de gráfico.

Os índices de salinidade, sodicidade, toxicidade e risco de infiltração para fins de irrigação foram interpretados conforme modelo proposto pela FAO (AYERS et al., 1991). Também foi utilizado o diagrama de Piper para classificação e comparação dos grupos de águas predominantes quanto aos cátions e ânions (PIPER, 1944). As análises estatísticas foram realizadas com o software RStudio e os diagramas foram gerados por meio do software livre Qualigraf 1.1.

\section{RESULTADOS E DISCUSSÃO}

Os resultados obtidos em relação às variáveis analisadas quanto à qualidade das águas do Rio Cuiabá no trecho metropolitano da capital mato-grossense permitiu identificar o potencial de uso da água para irrigação, além de possibilitar a adequação de práticas de manejo adequado (DIAS et al., 2013; ALMEIDA, 2010.).

Juntamente com isto, a qualidade da água para fins de irrigação transformada em um índice, faz com que este seja acessível pela comunidade interessada, ficando assim, de fácil entendimento. Os resultados para cada variável avaliada e para cada ponto estão apresentados na Tabela 2 , juntamente com os resultados para o teste estatístico Scott-Knott (5\%) realizado para conglomerado de médias referente aos períodos de seca, chuva e ambos, durante todo o período observado de 2011 a 2017.

Quanto à salinidade e toxicidade, conforme classificação da FAO proposta por Ayers et al. (1991), todos os pontos apresentaram nenhum risco de salinidade, infiltração ou toxicidade por Sódio, Cloretos e $\mathrm{pH}$. A temperatura média variou entre $27{ }^{\circ} \mathrm{C}$ para os períodos de seca e $28{ }^{\circ} \mathrm{C}$ para o período de chuva, onde foi constatado que não houve diferença significativa entre os períodos e pontos. Melo et al. (2009), citado por Silva et al.(2014) afirmam que temperaturas abaixo de $18{ }^{\circ} \mathrm{C}$ e acima de $24{ }^{\circ} \mathrm{C}$ podem afetar a absorção de nutriente. Valores médios superiores foram encontrados por Queiroz et al. (2018) em águas superficiais 
em uma comunidade quilombola de Mato Grosso, no qual o autor sugere a irrigação noturna como alternativa a diminuição dos possíveis impactos da temperatura sobre a cultura.

Tabela 2: Estatística descritiva da qualidade da água dos pontos avaliados no Rio Cuiabá, na região metropolitana da capital de Mato Grosso.

\begin{tabular}{|c|c|c|c|c|c|c|c|c|c|c|c|}
\hline \multirow{2}{*}{ Variáveis } & \multirow{2}{*}{ Época } & \multicolumn{10}{|c|}{ Pontos } \\
\hline & & \multicolumn{2}{|c|}{ EJCSG } & \multicolumn{2}{|c|}{ ERC } & \multicolumn{2}{|c|}{ EJCB } & \multicolumn{2}{|c|}{ EJCMP } & \multicolumn{2}{|c|}{ EPC } \\
\hline \multirow[t]{2}{*}{$\mathrm{T}\left({ }^{\circ} \mathrm{C}\right)^{\mathrm{NS}}$} & Seca & $27.67 a^{*}$ & \multirow{2}{*}{$\begin{array}{l}A \\
27,93\end{array}$} & $27,10 \mathrm{a}$ & \multirow{2}{*}{$\begin{array}{l}A \\
27,73\end{array}$} & 27,39 a & \multirow{2}{*}{$\begin{array}{l}\text { A } \\
27,85\end{array}$} & $27,02 \mathrm{a}$ & \multirow{2}{*}{\begin{tabular}{|l} 
A \\
27,4 \\
\end{tabular}} & 27,69 a & \multirow{2}{*}{$\begin{array}{l}\text { A } \\
27,92\end{array}$} \\
\hline & Chuva & $28.33 \mathrm{a}$ & & $28,63 \mathrm{a}$ & & $28,54 \mathrm{a}$ & & $27,97 \mathrm{a}$ & & $28,27 a$ & \\
\hline \multirow[t]{2}{*}{$\mathrm{Na}^{+}\left(\mathrm{mg} \mathrm{L}^{-1}\right)$} & Seca & $3.68 \mathrm{a}$ & \multirow{2}{*}{$\begin{array}{l}\text { A } \\
3.12\end{array}$} & $1.74 \mathrm{a}$ & \multirow{2}{*}{$\begin{array}{l}\mathrm{B} \\
1.73\end{array}$} & $3.46 \mathrm{a}$ & \multirow{2}{*}{$\begin{array}{l}\text { A } \\
3.08\end{array}$} & $1.29 \mathrm{a}$ & \multirow{2}{*}{$\begin{array}{l}\text { B } \\
1.38\end{array}$} & $1.05 \mathrm{a}$ & \multirow{2}{*}{$\begin{array}{l}\text { B } \\
1.15\end{array}$} \\
\hline & Chuva & $2.816 \mathrm{a}$ & & $1.70 \mathrm{a}$ & & $2.40 \mathrm{a}$ & & $1.56 \mathrm{a}$ & & $1.33 \mathrm{a}$ & \\
\hline \multirow[t]{2}{*}{$\mathrm{K}\left(\mathrm{mg} \mathrm{L}^{-1}\right)^{\mathrm{NS}}$} & Seca & $2.29 \mathrm{a}$ & \multirow{2}{*}{$\begin{array}{l}A \\
2.28\end{array}$} & $2.30 \mathrm{a}$ & \multirow{2}{*}{\begin{tabular}{|l|}
$\mathrm{A}$ \\
2.21 \\
\end{tabular}} & $2.46 \mathrm{a}$ & \multirow{2}{*}{$\begin{array}{l}A \\
2.37\end{array}$} & $2.02 \mathrm{a}$ & \multirow{2}{*}{$\begin{array}{l}\mathrm{A} \\
2.04 \\
\end{array}$} & $2.08 \mathrm{a}$ & \multirow{2}{*}{$\begin{array}{l}\mathrm{A} \\
1.97 \\
\end{array}$} \\
\hline & Chuva & $2.27 \mathrm{a}$ & & $2.03 \mathrm{a}$ & & $2.19 \mathrm{a}$ & & $2.06 \mathrm{a}$ & & $1.76 \mathrm{a}$ & \\
\hline \multirow[t]{2}{*}{$\mathrm{Ca}^{+2}\left(\mathrm{mg} \mathrm{L}^{-1}\right)$} & Seca & $8.27 \mathrm{a}$ & & $8.68 \mathrm{a}$ & A & $9.23 \mathrm{a}$ & $A$ & $8.19 \mathrm{a}$ & $A$ & $8.14 \mathrm{a}$ & $A$ \\
\hline & Chuva & $6.71 \mathrm{~b}$ & & $6.15 b$ & 7.79 & $6.59 \mathrm{~b}$ & 8.30 & $5.68 \mathrm{~b}$ & 7.31 & $5.83 \mathrm{~b}$ & 7.33 \\
\hline $\mathrm{Mg}^{+2}\left(\mathrm{mg} \mathrm{L}^{-1}\right)^{\mathrm{NS}}$ & Seca & $2.52 \mathrm{a}$ & $A$ & $2.69 \mathrm{a}$ & $A$ & $2.81 \mathrm{a}$ & $\mathrm{A}$ & $2.53 \mathrm{a}$ & A & $2.71 \mathrm{a}$ & $A$ \\
\hline & Chuva & $2.58 \mathrm{a}$ & 2.54 & $2.52 \mathrm{a}$ & 2.63 & $2.52 \mathrm{a}$ & 2.71 & $2.32 \mathrm{a}$ & 2.46 & $2.83 a$ & 2.76 \\
\hline $\mathrm{Cl}^{-}\left(\mathrm{mg} \mathrm{L}^{-1}\right)$ & Seca & $1.56 \mathrm{~b}$ & $A$ & $1.05 \mathrm{~b}$ & B & $2.68 a$ & A & $0.91 \mathrm{~b}$ & B & $0.85 \mathrm{~b}$ & B \\
\hline & Chuva & $2.82 \mathrm{a}$ & 2.06 & $0.92 \mathrm{~b}$ & 0.99 & $1.46 \mathrm{~b}$ & 2.18 & $1.02 \mathrm{~b}$ & 0.96 & $0.65 \mathrm{~b}$ & 0.77 \\
\hline $\mathrm{SO}_{4}^{++}\left(\mathrm{mg} \mathrm{L}^{-1}\right)^{\mathrm{NS}}$ & Seca & $1.82 \mathrm{a}$ & A & $3.56 \mathrm{a}$ & $A$ & $4.34 \mathrm{a}$ & $A$ & $3.26 \mathrm{a}$ & A & $2.88 \mathrm{a}$ & $A$ \\
\hline & Chuva & $3.51 \mathrm{a}$ & 2.51 & $4.37 \mathrm{a}$ & 3.90 & $4.14 \mathrm{a}$ & 4.22 & $4.03 \mathrm{a}$ & 3.58 & $3.60 \mathrm{a}$ & 3.18 \\
\hline $\mathrm{pH}$ & Seca & $7.53 \mathrm{a}$ & A & $7.40 \mathrm{~b}$ & A & $7.63 \mathrm{a}$ & $A$ & $7.65 \mathrm{a}$ & A & $7.70 \mathrm{a}$ & $A$ \\
\hline & Chuva & $7.25 b$ & 7.42 & $7.13 a b$ & 7.29 & $7.27 \mathrm{~b}$ & 7.48 & $7.29 \mathrm{~b}$ & 7.51 & $7.32 \mathrm{~b}$ & 7.54 \\
\hline E.Coli & Seca & $5930 \mathrm{c}$ & B & $1683 c$ & $C$ & 13989 a & $A$ & $2543 c$ & $C$ & $140 \mathrm{c}$ & $C$ \\
\hline (NMP/100 mL) & Chuva & $8206 \mathrm{~b}$ & 6861 & $3565 \mathrm{c}$ & 2453 & $13727 \mathrm{a}$ & 12882 & $1877 \mathrm{c}$ & 2270 & $633 c$ & 341 \\
\hline $\mathrm{N}$-total $\left(\mathrm{mg} \mathrm{L}^{-1}\right)$ & Seca & $0.94 \mathrm{a}$ & A & $1.00 \mathrm{a}$ & A & $2.41 \mathrm{a}$ & A & $1.53 \mathrm{a}$ & A & $0.52 \mathrm{a}$ & A \\
\hline & Chuva & $1.45 \mathrm{a}$ & 1.17 & $0.99 \mathrm{a}$ & 0.99 & $1.28 \mathrm{a}$ & 1.92 & $1.19 \mathrm{a}$ & 1.39 & $0.76 a$ & 0.66 \\
\hline P-total (mg L-1) & Seca & $0.26 \mathrm{a}$ & $A$ & $0.18 \mathrm{a}$ & A & $0.29 \mathrm{a}$ & A & $0.15 \mathrm{a}$ & A & $0.14 \mathrm{a}$ & A \\
\hline & Chuva & $0.31 \mathrm{a}$ & 0.28 & $0.30 \mathrm{a}$ & 0.23 & $0.30 \mathrm{a}$ & 0.29 & $0.21 \mathrm{a}$ & 0.17 & $0.36 \mathrm{a}$ & 0.23 \\
\hline Turbidez (UNT) & Seca & $15.46 \mathrm{~b}$ & $A$ & $21.21 \mathrm{~b}$ & $A$ & $12.50 \mathrm{~b}$ & $A$ & $14.91 \mathrm{~b}$ & $A$ & $21.29 \mathrm{~b}$ & \\
\hline & Chuva & $69.33 \mathrm{a}$ & 37.50 & $64.44 \mathrm{a}$ & 38.90 & $49.556 \mathrm{a}$ & 27.66 & $56.44 \mathrm{a}$ & 31.90 & $74.33 \mathrm{a}$ & 42.99 \\
\hline ST (mg L) & Seca & $94.62 \mathrm{~b}$ & $A$ & $21.21 \mathrm{~b}$ & $A$ & $84.85 \mathrm{a}$ & $A$ & $74.54 \mathrm{~b}$ & $A$ & $72.5 \mathrm{~b}$ & \\
\hline & Chuva & $133.33 \mathrm{a}$ & 110.45 & $130.87 \mathrm{a}$ & 101.43 & $115.22 \mathrm{~b}$ & 97.27 & $106.33 \mathrm{a}$ & 87.54 & $113.25 \mathrm{a}$ & 88.80 \\
\hline $\mathrm{CE}\left(\mathrm{dS} \mathrm{m}^{-1}\right)$ & Seca & $0.09 \mathrm{~b}$ & B & $0.09 \mathrm{~b}$ & B & $0.12 \mathrm{a}$ & A & $0.09 \mathrm{~b}$ & B & $0.08 \mathrm{~b}$ & B \\
\hline & Chuva & $0.09 \mathrm{~b}$ & 0.09 & $0.06 \mathrm{c}$ & 0.08 & $0.08 \mathrm{~b}$ & 0.11 & $0.06 \mathrm{c}$ & 0.08 & $0.05 \mathrm{c}$ & 0.07 \\
\hline RAS & Seca & $0.22 \mathrm{a}$ & A & $0.13 \mathrm{~b}$ & B & $0.24 \mathrm{a}$ & A & $0.10 \mathrm{~b}$ & B & $0.08 \mathrm{~b}$ & B \\
\hline & Chuva & $0.29 a$ & 0.24 & $0.15 b$ & 0.14 & $0.21 \mathrm{a}$ & 0.23 & $0.14 \mathrm{~b}$ & 0.11 & $0.12 \mathrm{~b}$ & 0.09 \\
\hline
\end{tabular}

NS Não significativo pelo teste de Scott-knott a $5 \%$ de probabilidade. ${ }^{*}$ Médias seguidas pela mesma letra minúscula na vertical, para cada variável, não diferem estatisticamente ente si pelo teste de Scott-Knott (5\%) e médias seguidas da mesma letra maiúscula na horizontal, para as estações, não diferem estatisticamente entre si pelo teste de Scott-Knott $(5 \%)$.

Os valores médios obtidos para o $\mathrm{pH}$ variaram nos pontos EJCSG, EJCB, EJCMP e EPC entre o período de seca e chuva, com médias semelhantes entre estes no período de seca e para o período de chuva, apenas ERC permaneceu sem distinção em ambos os períodos, no entanto, quando avaliado ambos os períodos, nenhum ponto se diferenciou estatisticamente. Os valores médios registrados variaram entre 7,13 a 7,70, e se encontram dentro da faixa recomendada por Ayers et al. (1991). Valores de pH acima de 8,3 podem diminuir a disponibilidade de micronutrientes como zinco, cobre, manganês, ferro e boro para as plantas (DIAS et al., 2013), além disso, águas usadas para irrigação com pH em faixas superiores a 8,0 o risco de obstrução de emissores é mais provável, pois corresponde ao pH de uma água em equilíbrio com calcário finamente moído (BUCKS et al., 1986, citado por BUSATO et al., 2010).

Os valores de cálcio estão dentro da faixa recomendada por Ayers et al. (1991), de 0-20 mmol $\mathrm{L}^{-1}$, sendo que as médias se apresentam maiores nos períodos de seca, a mais alta apresentou 9,23 mg L ${ }^{-1}(0,46$ $\left.\mathrm{mmol}_{\mathrm{C}} \mathrm{L}^{-1}\right)$ e, se diferem das médias mais baixas encontradas para os períodos de chuva, no entanto, ao avaliar 
ambos os períodos, não há diferença considerável entre as médias encontradas. Resultados semelhantes de cálcio foram encontrados por Parreira et al. (2017) ao avaliar águas do córrego do Sapo para fins de irrigação.

O magnésio, de acordo com o limite de 0 a $5 \mathrm{mmol}_{\mathrm{C}} \mathrm{L}^{-1}$, apresentado por Ayers et al. (1991) para qualidade da água de irrigação, se apresentou dentro do padrão recomendado. Suas médias não se diferenciaram nos períodos de seca e chuva, apresentando valor médio mais alto de $2,83 \mathrm{mg} \mathrm{L}^{-1}(0,072 \mathrm{mmolc}$ $\left.\mathrm{L}^{-1}\right)$ e 2,31 $\mathrm{mg} \mathrm{L}^{-1}\left(0,059 \mathrm{mmolc}^{-1}\right)$ para a mais baixa. Para o mesmo autor, quando são encontrados solos com teores elevados de magnésio em águas de irrigação, a produtividade das culturas tende a diminuir nestes solos. Valores semelhantes também foram registrados por Arraes et al. (2009) na parte alta da Bacia do Rio Curu/CE, onde os todos pontos observados estão abaixo do limite de restrição para uso na irrigação.

Quanto ao potássio, para o qual os mesmos autores recomendam a faixa de 0 a $2 \mathrm{mg} \mathrm{L}^{-1}$, apenas o ponto EPC no período de chuva se apresentou dentro do limite recomendado, apresentando média de 1,76 $\mathrm{mg} \mathrm{L}^{-1}$. Nos demais pontos, em ambos os períodos, as médias permaneceram acima do limite recomendado para irrigação, sem variações significativas. Valores contrários foram encontrados por Nunes et al. (2005) em poços tubulares e no Rio Gorutuba em Minas Gerais, sendo que os teores de $\mathrm{K}^{+}$observados foram baixos, sendo o cátion que menos contribuiu para a salinidade das águas de irrigação em todos os pontos avaliados.

A presença de cloretos está ligada tanto à lixiviação dos fertilizantes agrícolas que são aplicados no perímetro irrigado, quanto podem derivar de esgotos domésticos ou industriais (CARVALHO et al., 2017; SILVA et al., 2014). Os valores referentes a cloretos nos pontos EJCSG e EJCB foram superiores e teve diferença das médias dos demais pontos, tanto na comparação de seca e chuva, quanto no âmbito geral. No período chuvoso, o ponto EJCSG apresentou média de 2,81 $\mathrm{mg} \mathrm{L}^{-1}\left(0,55 \mathrm{mmol}_{\mathrm{c}} \mathrm{L}^{-1}\right)$ similar, de acordo com o Teste Scott-Knott, ao ponto EJCB no período de seca, 2,68 $\mathrm{mg} \mathrm{L}^{-1}\left(0,526 \mathrm{mmol}_{\mathrm{C}} \mathrm{L}^{-1}\right)$. O recomendado por Ayers et al. (1991), é de 0 a $30 \mathrm{mmol}_{\mathrm{C}} \mathrm{L}^{-1}$, no entanto, ambos os pontos apresentaram valores abaixo do recomendado. Para Antas et al. (2011), o cloreto não é retido ou adsorvido pelo solo, se deslocando por meio da água, que é absorvido pelas plantas, o qual se acumula, e caso haja excesso pode gerar necrose e queimaduras nas folhas. No entanto, os pontos com maiores médias estão localizados a margem do perímetro urbano de Cuiabá/MT, podendo estar relacionado a ações antrópicas, como descargas de esgotos próximas aos pontos, o mesmo observado por Arraes et al. (2009), na parte baixa da bacia do Rio Curu/CE. Sulfatos se apresentaram com médias iguais para todos os pontos tanto nos períodos de seca e chuva, quanto de forma geral. $O$ intervalo recomendado para águas com fins de irrigação é de $0-20 \mathrm{mmol}_{\mathrm{C}} \mathrm{L}^{-1}$ (AYERS et al., 1991). O ponto ERC apresentou a maior média, 4,37 $\mathrm{mg} \mathrm{L}^{-1}$ e EJCSG a menor, 1,81 $\mathrm{mg} \mathrm{L}^{-1}$.

Ayers et al. (1991) recomendam intervalos de 1 a $10 \mathrm{mg} \mathrm{L}^{-1}$ para Nitrogênio total e 0 a $2 \mathrm{mg} \mathrm{L}^{-1}$ para Fósforo total. Os valores médios de fósforo encontrados não tiveram variações significativas entre os períodos, da mesma maneira se comportou as médias encontradas para Nitrogênio Total. Ambas as variáveis não ultrapassaram o intervalo recomendado para uso na irrigação. Para Resende (2002), o fósforo é fortemente retido pelo solo, e sua lixiviação em solos tropicais tem magnitude desprezível, gerando desequilíbrios em ecossistemas aquáticos devido ao processo de eutrofização, assim como a descarga de nitrogênio em águas superficiais pode levar ao crescimento excessivo de algas como também a eutrofização 
desses sistemas, causando entupimento de emissores na irrigação (GIRÃO et al., 2007).

As médias de turbidez, assim como de Sólidos Totais apresentaram-se mais baixas no período de seca em relação ao período de chuva nos pontos avaliados. No entanto, de maneira geral, se comportaram estatisticamente iguais em todos os pontos. No período chuvoso, todos os pontos registraram médias de turbidez superiores a 40 UNT, para águas de Classe 1 como regulamenta a Resolução n. 357 do CONAMA (BRASIL, 2005), restringindo a, conforme traz o regulamento a "irrigação de hortaliças consumidas cruas e de frutas que se desenvolvam rentes ao solo e que sejam ingeridas cruas sem remoção de película", podendo ser utilizada sem restrições apenas no período de seca, onde a média máxima chegou a 21,29 UNT.

Já para sólidos totais, avaliando a recomendação de Almeida (2010) para sólidos em suspensão, apenas o ponto ERC não possui restrições de uso quanto ao risco de criação de problemas de entupimento nos sistemas de irrigação localizada, já os demais no período de seca possuem restrição moderada e no período chuvoso todos se enquadram em restrições severas. O mesmo comportamento para turbidez e sólidos totais foi verificado por Franco et al. (2012), ao avaliar a qualidade da água microbacia do Coqueiro em São Paulo, onde ocorreram variações de médias entre pontos e também entre período chuvoso e seco, no entanto, todos os pontos houve baixo potencial de risco de obstrução de emissores, conforme estudo de Barboza et al. (2011) para a mesma bacia.

A RAS obteve médias semelhantes, mas altas nos pontos EJCSG e EJCB, se distinguindo das médias encontradas nos demais pontos. De acordo com Almeida (2010), a RAS indica a proporção relativa que se encontra o Sódio em relação com o Cálcio e o Magnésio, e quando há a predominância do íon sódio, induzirá trocas de íons cálcio e magnésio pelo de sódio no solo, podendo gerar a degradação do mesmo. Nestes mesmos pontos, o sódio também se encontra com média mais alta que os demais, o que pode estar gerando o aumento da RAS. No entanto, ao avaliar a salinidade nenhum dos pontos possuem restrições para uso das águas na irrigação.

Quanto aos aspectos microbiológicos, os valores encontrados para a bactéria Escherichia coli nos pontos avaliados foram divididos em três grupos conglomerados de médias, sendo que o ponto EJCB se destacou com médias mais altas tanto no período seco quanto chuvoso, 13.989 e $13.727 \mathrm{NPM} / 100 \mathrm{~mL}$ respectivamente, superando os limites para águas doces estabelecidas na Resolução 357 (BRASIL, 2005), já os pontos EJSCG na seca, ERC, EJCMP e EPC em ambos os períodos apresentaram médias semelhantes variando entre 140, a menor, e 5.930 a maior. O ponto EJCSG no período chuvoso apresentou média de 8.206 ficando entre os conglomerados de maiores e menores médias. Apenas o ponto EPC, no período seco apresentou baixa concentração de coliformes fecais (140 NPM/100 mL), ficando sem restrições para irrigação.

Avaliando o risco de entupimento de emissores por populações bacterianas (ALMEIDA, 2010), os pontos EJCSG, ERC, EJCMP e EPC não apresentam nenhum risco, ficando apenas o ponto EJCB com risco moderado. Salienta-se ainda que a localização dos pontos onde foram encontradas as maiores médias são os localizados nas áreas de margens mais urbanizadas da cidade de Cuiabá, como também foi verificado por Oliveira et al. (2017) ao avaliarem aspectos microbiológicos das águas do Rio Cuiabá em quatro pontos no 
perímetro urbano, com resultados bem acima do limite estipulado pelo CONAMA (2017). O aumento da presença de coliformes termotolerantes são os principais indicadores do lançamento de esgotos domésticos sem tratamento (CETESB, 2015). O diagrama de Piper foi utilizado para classificar e identificar distintos grupos de águas quanto ao seu conteúdo iônico. Os pontos avaliados no Rio Cuiabá foram classificados conforme apresentado na Figura 2.

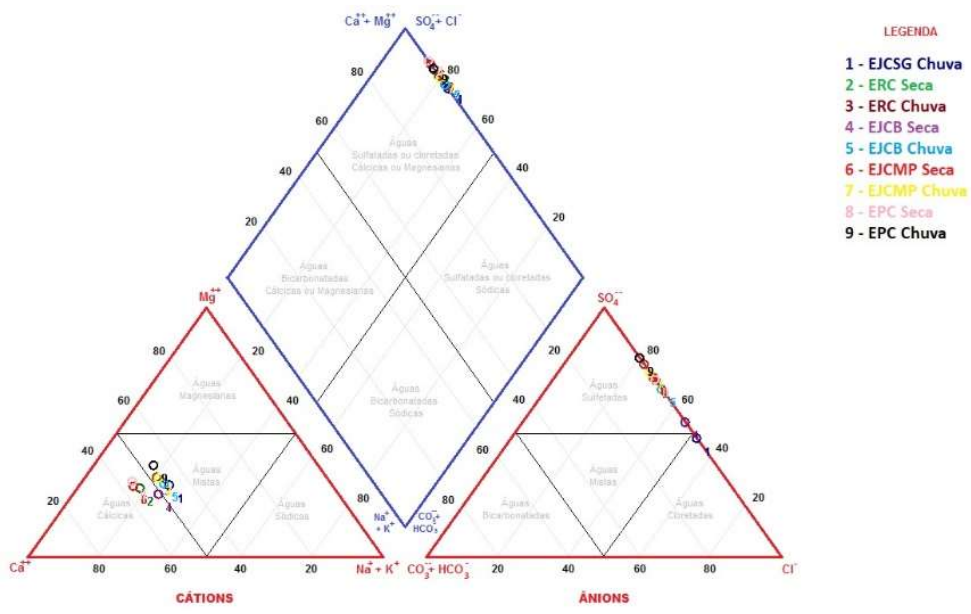

Figura 2: Classificação das águas do Rio Cuiabá conforme diagrama de Piper.

A classificação das fácies hidroquímicas das águas conforme gerado pelo diagrama de Piper, no período de seca há dominância de águas mista Sulfatada e no período de chuva, são em maioria águas Cálcica Sulfatadas. Apenas o ponto EJCSG não houve diferença hidroquímica para o período de seca ou chuva, e se diferenciou da classificação dos demais, sendo águas de propriedades Mistas Cloretadas. Mudanças na dominância iônica entre períodos chuvosos e secos também foram observados por Santos (2017), no reservatório do Poção da Ribeira em Sergipe, no qual o mesmo ainda atribui esse fator tendo como provável causa a interação das águas pluviométricas ao longo da bacia de drenagem, sugerindo a existência de um fenômeno de troca iônica responsável pela alternância das faces das águas.

\section{CONCLUSÕES}

A água do Rio Cuiabá, no trecho avaliado, quanto aos aspectos físico-químicos, de maneira geral, não possuem restrições de uso para fins de irrigação. Constatou-se que em nenhum dos pontos avaliados há riscos de salinidade, sodicidade, infiltração ou toxicidade quanto ao uso das águas para fins de irrigação. Os valores obtidos para a bactéria E.Coli demonstram que o rio se encontra contaminado, não podendo ser utilizado para fins de irrigação e outras finalidades, no qual apenas o ponto EPC no período de seca sem restrições.

Sugere-se que sejam realizadas investigações mais aprofundadas acerca das finalidades de uso das águas do Rio Cuiabá e quais tipos de cultivos estão sendo irrigados, visto que pequenos olericultores se instalam próximos às áreas urbanas da cidade e podem estar utilizando destas águas em suas culturas, contaminando-as. 
AGRADECIMENTOS: à Coordenação de Aperfeiçoamento de Pessoal de Nível Superior - Brasil (CAPES) -

Código de Financiamento 001, em bolsa concedida à primeira autora.

\section{REFERÊNCIAS}

ANA. Agência Nacional de Águas. Atlas irrigação: uso da água na agricultura irrigada. Brasília: ANA, 2017.

ALMEIDA, D. J. A.; DALLEMOLE, D.; ZAVALA, A. A. Z.. Urban and periurban agriculture study on Várzea Grande (MT) under the perspective of cluster analysis. Revista IberoAmericana de Ciências Ambientais, v.7, n.2, p.225-241, 2016. DOI: http://doi.org/10.6008/SPC2179$\underline{6858.2016 .002 .0019}$

ALMEIDA, O. A.. Qualidade da água de irrigação. Salvador: Embrapa Mandioca e Fruticultura, 2010.

AMORIM, A. P. L. R.. As Perspectivas para o Saneamento na Bacia Hidrográfica do Rio Paraguai (BAP) em Mato Grosso Após a Edição da Lei Federal de Saneamento Básico Nº 11445/2007. Monografia (Graduação em Engenharia Sanitária e Ambiental) - Universidade Federal de Mato Grosso, Cuiabá, 2013.

ANTAS, F. P. S.; MORAIS, E. R. C.. Monitoramento da qualidade química da água para fins de irrigação no Rio Açú, RN. HOLOS, v.4, p.23-28, 2011.

ARAUJO, G. C.; ZEILHOFER, P.. Padrões espaciais da qualidade da água na bacia do rio Cuiabá e rio São Lourenço-Mato Grosso. Hygeia, v.7, n.13, 2011.

ARRAES, F. D. D.; ANDRADE, E. M.; PALÁCIO, H. A. Q.; FROTA JUNIOR, J. I.; SANTOS, J. C. N.. Identificação dos íons determinantes da condutividade elétrica nas águas superficiais da bacia do Curu, Ceará. Revista Ciência Agronômica, v.40, n.3, p.346-355, 2009.

AYERS, R. S.; WESTCOT, D. W.. A qualidade da água na agricultura. Campina Grande: UFPB, 1991.

BARBOZA, G. C.; HERNANDEZ, F. B. T.; FRANCO, R. A. M. Análise dos riscos à sistemas de irrigação causados pela qualidade da água do córrego do Coqueiro/SP. Revista Brasileira de Agricultura Irrigada-RBAI, v.5, n.1, 2013.

BRASIL. Ministério do Meio Ambiente. CONAMA. Resolução n. 357 de 17 de março de 2005. Brasília: DOU, 2005.

BRASIL. Ministério do Meio Ambiente. Plano de conservação da Bacia do Alto Paraguai (Pantanal): PCBAP. Brasília, 1997.

BUSATO, C. C. M.; SOARES, A. A.. Desempenho de gotejadores utilizando água de baixa qualidade química e biológica. Bioscience Journal, Uberlândia, v.26, n.5, p.739746, 2010.

CARVALHO, L. L. S.; LACERDA, C. F.; ANDRADE, E. M.; LOPES, F. B.. Variabilidade espacial e temporal da qualidade da água de poços no perímetro irrigado do baixo Acaraú/CE. Revista Brasileira de Agricultura Irrigada-RBAI, Fortaleza, v.11, n.2, 2017. DOI: http://doi.org.10.7127/rbai.v11n200623

CAVINATTO, V.. Caracterização Hidrográfica do Estado de
Mato Grosso. Cuiabá: Prodeagro, 1995.

CETESB. Companhia Ambiental do Estado de São Paulo. Qualidade das águas superficiais no estado de São Paulo 2014. São Paulo: CETESB, 2015.

DIAS, N. S.; BRIGIDO, A. R.; SOUZA, A. C. M.. Manejo e conservação dos solos e da água. São Paulo: Livraria da Física, 2013.

FRANCO, R. A. M.; HERNANDEZ, F. B. T.. Qualidade de água na microbacia do Coqueiro, noroeste do Estado de São Paulo. Water Resources and Irrigation Management, v.1, n.1, p.61-69, 2012

GIRÃO, E. G.; ANDRADE, E. M.; ROSA, M. F.; ARAÚJO, L. F. P.; MEIRELES, A. C. M.. Seleção dos indicadores da qualidade de água no Rio Jaibaras pelo emprego da análise da componente principal. Revista Ciência Agronômica, v.38, n.1, p.17-24, 2007

KREISCHER, T. C. V.; GONÇALVES, D. M. M.; VALENTINI, C. M. A.. Aspectos hidroambientais do córrego Barbado em Cuiabá/MT. HOLOS, v.1, p.86-109, 2012. DOI: https://doi.org/10.15628/holos.2012.697

MARCHETTO M.; NOQUELLI, L. H. M.; ALVES, M. F.. Qualidade e Enquadramento dos Recursos Hídricos na Bacia do Rio Cuiabá e seus usos Preponderantes. E\&S Engineering and Science, v.8, n.3, p.2-20, 2019.

MARCHETTO, M.; NOQUELLI, L. H. M.; ANDRADE, L. A. Z.; SILVA, M. A.; SOARES, S. R. A.; EVANGELISTA, R. M.. Avanços e desafios da Política de Recursos Hídricos quanto aos instrumentos de gestão. In: FIGUEIREDO, D. M.; DORES, E. F. G. C.; LIMA, Z. M.. Bacia do Rio Cuiabá: uma abordagem socioambiental. Cuiabá: UFMT, 2018. p. 498-518.

MATO GROSSO. Empresa Mato-Grossense de Pesquisa, Assistencia e Extensao Rural S/A. Projeto de Recuperação e Conservação da Bacia do Rio Cuiabá. Cuiabá: EMPAER-MT, 1996.

MATO GROSSO. Secretaria Estadual de Meio Ambiente. Superintendência de Recursos Hídricos. Relatório de Monitoramento da Qualidade da Água do Estado de Mato Grosso. Cuiabá: SEMA, 2018

NUNES, W. A. G. A.; KER, J. C.; NEVES, J. C. L.; RUIZ, H. A.; FREITAS, G. A.; BEIRIGO, R. M.. Qualidade da água de irrigação de poços tubulares e do rio Gorutuba na região de Janaúba/MG. Irriga, v.10, n.4, p.419-426, 2005. DOI: https://doi.org/10.15809/irriga.2005v10n4p419-426

OLIVEIRA, W. F.; PINTO, O. B.. Análise microbiológica da qualidade das águas do rio Cuiabá perímetro urbano, a partir de quatro pontos de amostragem. Uniciências, v.21, n.2, p.56-59, 2017.

PARREIRA, T. P.; SANTOS, G. O.; SANTOS, A. R. F.. qualidade 
e disponibilidade da água para irrigação no córrego do Sapo, Rio Verde, Goiás. Caminhos de Geografia, v.18, n.64, p.3446, 2017.

PIPER, A. M.. A graphic procedure in the geochemical interpretation of water analyses. Transactions. American Geophysical Union 25, 1944.

QUEIROZ, T. M.; MELO, M. T.; FERREIRA, F. S.. Qualidade da água para irrigação na comunidade quilombola Vão Grande, município de Barra do Bugres/MT. Revista Brasileira de Agricultura Irrigada-RBAI, v.12, n.3, 2018. DOI: http://doi.org/10.7127/rbai.v12n300733

RESENDE, A. V.. Agricultura e qualidade da água: contaminação da água por nitrato. Planaltina: Embrapa
Cerrados, 2002.

SANTOS, C. E. O.. Geoquímica das águas do reservatório Poção da Ribeira, Agreste Central de Sergipe. Scientia Plena, v.13, n.10, 2017. DOI:

http://dx.doi.org/10.14808/sci.plena.2017.109906

SILVA, I. N.; FONTES, L. O.; TAVELLA, L. B.; OLIVEIRA, J. B.; OLIVEIRA, A. C.. Qualidade de água na irrigação.

Agropecuária Científica no Semiárido, v.7, n.3, 2011. DOI: http://dx.doi.org/10.30969/acsa.v7i3.134

SILVA, L. R.; CUNHA, A. H. N.; SILVA, S. M. C.; SOUZA, J. M. F.. Avaliação de parâmetros físico-químicos da água de irrigação utilizada em um pivô central em Goiânia/GO. Global Science and Technology, v.7, n.3, 2014

A CBPC - Companhia Brasileira de Produção Científica (CNPJ: 11.221.422/0001-03) detém os direitos materiais desta publicação. Os direitos referem-se à publicação do trabalho em qualquer parte do mundo, incluindo os direitos às renovações, expansões e disseminações da contribuição, bem como outros direitos subsidiários. Todos os trabalhos publicados eletronicamente poderão posteriormente ser publicados em coletâneas impressas sob coordenação da Sustenere Publishing, da Companhia Brasileira de Produção Científica e seus parceiros autorizados. Os (as) autores (as) preservam os direitos autorais, mas não têm permissão para a publicação da contribuição em outro meio, impresso ou digital, em português ou em tradução. 